\title{
Reduced Attention to Faces in Images is associated WITH PSYCHOPATHOLOGY
}

\author{
Marius Rubo \\ Clinical Psychology and Psychotherapy \\ University of Fribourg \\ Fribourg, Switzerland \\ marius.rubo@unifr.ch
}

Ivo Käthner

Department of Psychology I, Biological Psychology, Clinical Psychology and Psychotherapy

University of Würzburg

Würzburg, Germany

ivo.käthner@uni-wuerzburg.de

Simone Munsch

Clinical Psychology and Psychotherapy

University of Fribourg

Fribourg, Switzerland

simone.munsch@unifr.ch

\begin{abstract}
Humans show a robust tendency to attend to faces in images, but also differ consistently in the strength of this attentional preference. Previous research remained inconclusive as to how a stronger attentional preference for faces may be indicative of an individual's personality or clinical characteristics. Here we investigated attention towards faces in 120 participants who freely viewed photos showing a person in the context of a complex and visually rich environment. Participants differed consistently in the strength of their attention to faces across images with $\alpha=0.88$. A stronger preference for faces was correlated positively with openness to experience, extraversion, agreeableness and empathizing and was correlated negatively with social anxiety, depression levels and alexithymia. A common factor, which may be best understood as general psychopathology, explained $41 \%$ of the variance in these variables and was correlated with face preference at $\mathrm{r}=-0.36$. Social anxiety stood out as only variable which explained face preference above and beyond the Big Five personality factors. Future research should investigate how correlates of face preference generalize across different types of images and real-life social situations.
\end{abstract}

Keywords Face Preference · Personality Traits · Psychopathology · Social Anxiety · Browser-Based Image Viewing

\section{Introduction}

Human attention is robustly captured by faces (Cerf, Frady, and Koch 2009; Xu et al. 2014). A tendency to attend to faces can be observed from a very young age in human (Farroni et al. 2002; Hunnius and Geuze 2004) as well as nonhuman (Myowa-Yamakoshi et al. 2003) infants and provides a basis for every higher order social capability (Adolphs 2010). Attentional preference for faces was found to robustly vary between observers, with some people consistently allocating more time to attending to faces than others (Rubo and Gamer 2018; Haas et al. 2019; Guy et al. 2019). However, data on the significance of this attentional trait for psychological functioning remain fragmented. Different lines of research investigated relationships between face preference and personality traits as well as psychological constructs derived from clinical and social psychology, with overall inconclusive results. 
Using the Big Five personality traits consisting of extraversion, agreeableness, conscientiousness, neuroticism, and openness to experience, Wu et al. (2014) found a positive correlation between face preference and extraversion as well as agreeableness and a negative correlation with openness, whereas Guy et al. (2019) found only a negative correlation between face preference and conscientiousness and Haas et al. (2019) found no correlations between face preference and any Big Five personality trait. A prediction of personality traits from behavioral measures are of particular interest as they provide a parsimonious description of inter-individual differences which is widely used in social and clinical psychology (Matthews, Deary, and Whiteman 2003; Carver and Connor-Smith 2010) and generalizes well across cultures (Heine and Buchtel 2009).

Other studies have linked reduced face preferences to clinical descriptions of inter-individual variation. However, since different forms of psychopathology and personality traits are often correlated, specifically linking biomarkers to an isolated measurement of a specific form of psychopathology is often not possible (Caspi et al. 2014). In order to allow for a more comprehensive assessment of correlates of face preference, participants in the present study were characterized along a range of clinical and other variables which may be linked to the preferential processing of social information.

Social anxiety, a fear of social situations which is common in the general population (Stein, Walker, and Forde 1994) and, when pronounced and debilitating, can justify a diagnosis as social anxiety disorder (SAD) (Morrison and Heimberg 2013), was linked to eye contact avoidance in clinical reports (Schneier et al. 2011). Investigations of gaze towards social images, however, yielded mixed results with studies reporting a negative (Moukheiber et al. 2010; Weeks, Howell, and Goldin 2013), positive (Brunet et al. 2009; Wieser et al. 2009) or no (Guy et al. 2019; Rubo, Huestegge, and Gamer 2020) association with face preference. Enhanced sensitivity to social rejection, which is found in SAD, but also in major depression and other mental disorders (Hsu and Jarcho 2020), was associated with faster attention towards rejecting faces (Berenson et al. 2009; Ehrlich et al. 2015) as well as sad faces (Kraines, Kelberer, and Wells 2018). Trait anxiety was found to be associated with an attentional bias towards threat, including threatening faces (Bradley et al. 1998; MacLeod, Grafton, and Notebaert 2019). Depression levels were found to be associated with an attentional bias towards negative information, including sad faces (Joormann and Gotlib 2007; Foster et al. 2020). Disordered eating was reported to be associated with an attentional bias towards faces in general (Harrison et al. 2010), but also to rejecting faces (Cardi et al. 2012). Individuals with Autism Spectrum Disorder (ASD) are known to avoid eye contact in real social encounters (Volkmar et al. 2004; Hessels et al. 2018) and were also found to exhibit reduced attention towards faces in images (Senju and Johnson 2009; Wang et al. 2015), although findings are not entirely consistent (Rutherford and Krysko 2008) and more mixed with regards to autistic traits (Freeth, Foulsham, and Kingstone 2013; Hagen and Bright 2016; Guy et al. 2019). A contrasting juxtaposition between empathizing (the ability to recognize mental states in others and respond emotionally) and systemizing (the drive to analyze rule-based systems) is used to describe a variation in human mindsets on a scale which seamlessly transitions from the normal population to individuals with ASD (Greenberg et al. 2018). Other constructs used to describe differences between people can be assumed to be associated with a tendency for face preference. Alexithymia, the difficulties to identifying, differentiating and describing feelings (Bagby, Parker, and Taylor 2020), was found to be associated with low social functioning (Grynberg et al. 2012) and to predict poorer recognition of emotional expressions in faces (Fujiwara et al. 2017). Impulsivity may influence face preferences due to its association with inattention (Shalom et al. 2013). Social value orientation (SVO), the magnitude of concern people have for others (Murphy, Ackermann, and Handgraaf 2011), predicts cooperation in social dilemmas (Pletzer et al. 2018) and may be reflected in the seeking of social information, although a previous study found no correlation with attention to faces (Guy et al. 2019). Since general knowledge may reflect aspects of an individual's personality (Chamorro-Premuzic, Furnham, and Ackerman 2006; Furnham et al. 2008), it may likewise be reflected in attentional preferences.

Various methods exist to assess a preferential processing of faces. While some studies measured reactivity to external cues in the presence of social stimuli (Cardi et al. 2012; Ehrlich et al. 2015), others obtained gaze behavior in response to seeing faces (Brunet et al. 2009; Kraines, Kelberer, and Wells 2018). An increasing number of studies recorded gaze behavior in response to more naturalistic stimuli which encompass the complexity of everyday experiences rather than showing faces in isolation (e.g., Xu et al. 2014; Wang et al. 2015; Guy et al. 2019). In the present study, we additionally selected stimuli based on the presence of non-social areas which may draw attention away from faces, avoiding a situation where participants may attend to faces partly in response to a lack of other interesting areas to visually explore. We used a measurement technique where participants reveal their attentional preferences by moving a computer mouse to unblur individual areas in an otherwise blurred image (Schulte-Mecklenbeck, Murphy, and Hutzler 2011; Kim et al. 2017; Matzen, Stites, and Gastelum 2021), a technique which was found to approximate eye 
fixations towards unblurred images (Kim et al. 2017). This form of attentional assessment can be employed in internet-based experiments, allowing to reach wider and more diverse samples of participants while often preserving findings observed with conventional methods (Gosling and Mason 2015).

The present study assessed if attentional preferences for faces were associated with psychological traits. After inspecting if attention towards images in a web browser exhibited patterns known from eye-tracking studies (high consistency in face preferences across images and a stronger face preference towards direct compared to averted gaze) (Senju, Hasegawa, and Tojo 2005), gaze preferences were compared with participants' personality traits, social anxiety, rejection sensitivity, trait anxiety, depression levels, eating psychopathology, systemizing and empathizing, alexithymia, impulsivity, social value orientation and general knowledge. As a means for internal replication, analyses were separated between images depicting direct and averted gaze. We furthermore assessed if variables associated with a stronger preference for attending faces reflected a common psychological dimension and tested if any variables predicted gaze preferences above and beyond personality factors.

\section{Methods}

\subsection{Subjects, Materials and Procedure}

120 participants (100 females, 18 males, 2 persons who did not wish to disclose or did not identify with one of the two genders; mean age $=22.05$ years, $S D=5.92,110$ university students) took part in this study. Sample size and instruments were determined a priori and were pre-registered (AsPredicted \#55857, https://aspredicted.org/EZJ_ZVA). A sample size of $\mathrm{n}=120$ is sufficient to detect a correlation of $r$ $=.29$ with a Power of $90 \%$ and Alpha set to $5 \%$ in a two-sided comparison. Before valid datasets from 120 participants were obtained, we recorded data from an additional 6 participants which were excluded due to missing mouse movements in at least one trial. The study conformed to the principles expressed in the Declaration of Helsinki and was approved by the local ethics committee at the University of Fribourg (Ref-No. 2020-661R1). Participants entered the study through a weblink. They were informed that they could use a computer with a mouse (used by 44 participants) or a trackpad (used by 76 participants), but not a smartphone or tablet.

After completing an informed consent form and a demographic questionnaire, participants viewed 20 images for 10 seconds each in a randomized order. All images depicted one person with clearly visible face (for weblinks to images see Supplementary Methods 1.1), with people in 10 images looking directly into the camera (direct gaze) and people in the remaining 10 images looking elsewhere (averted gaze). All images were awarded by the Wikimedia Commons community (https://commons.wikimedia.org/) for their visual appeal and depicted a visually rich context (e.g., a store, a backyard, a garage). Images were blurred and only displayed at high acuity around the cursor position (see Figure 1). Image resolution was $1280 \times 720$ pixels. The blur effect was achieved using a Gaussian Blur filter with a radius of 20 pixels. The image area displayed at high acuity was defined by a circular mask with a diameter of 144 pixels. Mouse cursor positions were assessed continuously (recording $M=22.50$ ( $S D=1.72$ ) positions per second).

Subsequently, participants filled out questionaires assessing the Big Five Personality traits, Social Anxiety, Rejection Sensitivity, Trait Anxiety, Depression levels, Eating Psychopathology, Systemizing, Empathizing, Alexithymia, Impulsivity, Social Value Orientation and General Knowledge (see Supplementary Methods 1.2). Sample questionnaire descriptives are detailed in Supplementary Results 2.1.

\subsection{Data processing}

Attention in each sample was labelled to rest either on a face (if at least part of the face was made visible at a high acuity) or elsewhere. The temporal trajectory of attention showed a distinct pattern, with more time spent attending to a face during the first 5 seconds compared to the last 5 seconds (see Supplementary Results 2.2). Attention data were aggregated as percentage of time spent attending the face across the whole trial. Since data showed a right-skewed distribution (see Supplementary Results 2.3), they were log-transformed after adding one for the purpose of statistical analyses (while descriptive statistics and plots show untransformed data). Attention data were further averaged within participants and conditions (when comparing attention between conditions) or only within participants (when describing correlations between attention across all images and questionnaire data). 


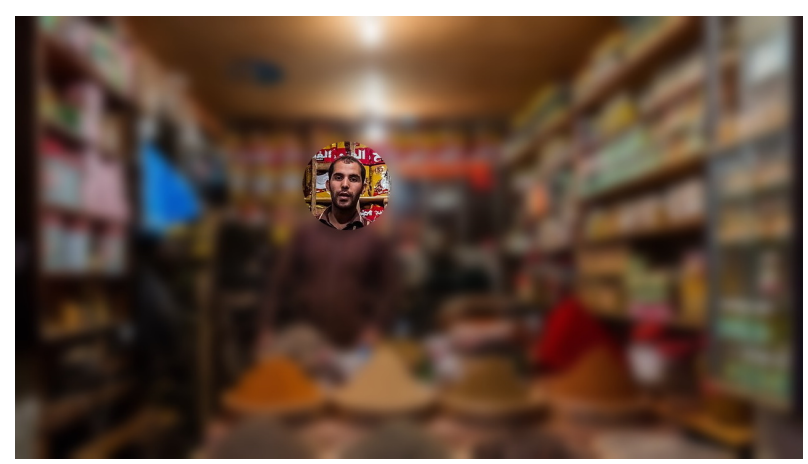

Figure 1: Example image. Using a mouse cursor, participants moved a circular mask which unblurred the otherwise blurred image. Visit https://www.rubo-research.com/AttentionParadigmExampleImage/ for a demonstration. Amount of time spent unblurring the face served as proxy for an attentional preference for faces. Image: Diego Delso, delso.photo, License CC-BY-SA.

\subsection{Data analysis}

Data were analyzed using $\mathrm{R}$ for statistical computing (version 3.2, Team and others 2013). Internal consistency of measures was assessed with Cronbach's $\alpha$. Time spent attending to faces in different conditions (direct versus averted gaze) was compared by means of a linear mixed model where participant ID was inserted as random effect and condition was inserted as fixed effect. Parameters were tested for significance using an $F$-test. Cohen's $d$ was defined as the mean difference between the two conditions divided by the standard deviation of the difference. Relationships between attention to faces and questionnaire data were tested using Neyman-Pearson correlations. Principal component analysis (PCA) was performed with the function princomp with no rotation applied. In all analyses, $\alpha$ was set to $5 \%$. Normality was inspected using Q-Q Plots.

Among the variables which were significantly correlated with attentional preferences towards faces, we employed a hierarchical data analysis strategy to test if personality factors alone allowed for the best prediction, or if any other questionnaire data exhibited predictive power above and beyond what was explained by personality factors. To this end we first performed an all-subsets multiple regression analyses including every combination of personality factors which were significantly correlated with attentional preferences towards faces. Model performance was evaluated by means of the RMSE criterion across leave-one-out cross-validated models (with data from one participant omitted from the training data set and used as sole test data set in each iteration). Next, all other variables which were significantly correlated with attentional preferences were added to the best-performing model from the first step in a second all-subsets multiple regression analyses.

\subsection{Data availability}

The data that support the findings of this study are available at https://osf.io/5gvwb/.

\section{Results}

\subsection{General properties of attention to faces}

Participants spent $16.76 \%(S D=6.21 \%)$ of the viewing time attending to faces, with more time spent viewing faces showing direct compared to averted gaze (see Supplementary Results 2.4). Internal consistency for attention towards faces was $\alpha=0.88$ across all images, $\alpha=0.80$ across images depicting direct gaze and $\alpha=$ 0.76 across images depicting averted gaze.

\subsection{Correlations between self-reports and attention to faces}

Across all images, attention to faces was positively correlated with extraversion, agreeableness, openness to experience and empathizing and negatively correlated with social anxiety, depression levels and alexithymia (see Figure 2 and Supplementary Results 2.5 for details). Correlation coefficients in the two sets of images 


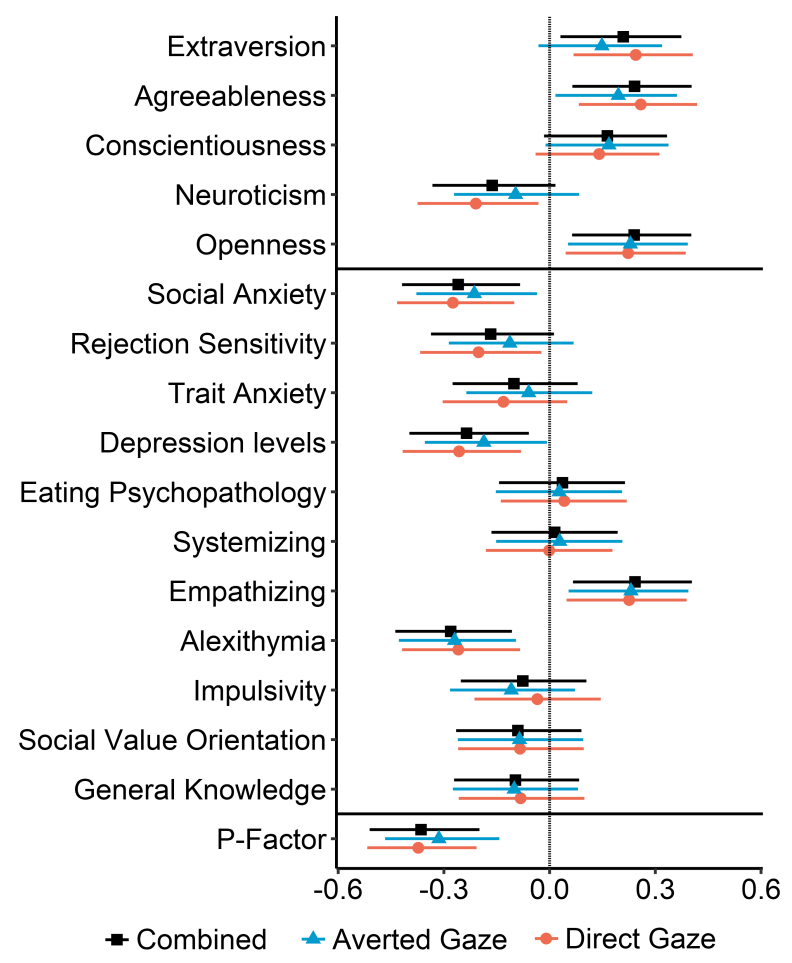

Figure 2: Correlations between attention towards faces and personality measures (above the first horizontal line), several clinical and other psychological measures as well as a general psychopathology factor ( $p$-factor, lowest line). Results are presented for attention to faces across all 20 images as well as for only the 10 images depicting averted and direct gaze, respectively. Error bars represent 95\%-CIs.

depicting direct and averted gaze were highly consistent $(\mathrm{r}=0.96,95 \%$ CI $[0.88,0.99], \mathrm{t}(14)=12.60, p<$ $.001)$.

\subsection{Factor structure among variables correlated with face preference}

Principal component analysis (PCA) was applied to the variables which were correlated significantly with attention towards faces across all images (extraversion, agreeableness, openness to experience, social anxiety, depression levels, empathizing, alexithymia). Based on a scree plot (Figure 3a), we identified one dominant factor which we labelled $p$-factor due to its resemblance with a general psychopathology factor described by Caspi et al. (2014). It explained $41.25 \%$ in the variance of the seven variables, while the following factors explained 15.09\%, 14.17\%, 10.33\%, 8.66\%, 5.72\% and 4.79\%. Extraversion, social anxiety, depression levels, empathizing and alexithymia all correlated strongest with this p-factor, while openness and agreeableness more strongly correlated with other factors (see Figure $3 \mathrm{~b}$ ). P was negatively correlated with attention to faces $(\mathrm{r}=-0.36,95 \%$ CI $[-0.51,-0.20], \mathrm{t}(118)=-4.26, p<.001)$.

\subsection{Predicting attention to faces beyond personality traits}

In a hierarchical analysis (for details see Supplementary Results 2.6), we assessed if any variable predicted attention towards faces above and beyond what was explained by personality factors alone (a particularly widely used and parsimonious characterization of differences between individuals). In an all-subsets multiple regression analyses using the three personality factors which correlated significantly with attention towards faces (extraversion, agreeableness and openness), the best-performing model incorporated only agreeableness $(\beta=0.25$ [95\%-CI 0.08, 0.42]) and openness $(\beta=0.25$ [95\%-CI 0.08, 0.42]). A second all-subsets multiple regression analyses adding all other variables which were correlated significantly with attention towards faces (social anxiety, depression levels, empathizing and alexithymia) found that only the inclusion of social anxiety $(\beta=-0.22[95 \%$-CI $-0.39,-0.05])$ led to an additional improvement in the model's predictive accuracy. 


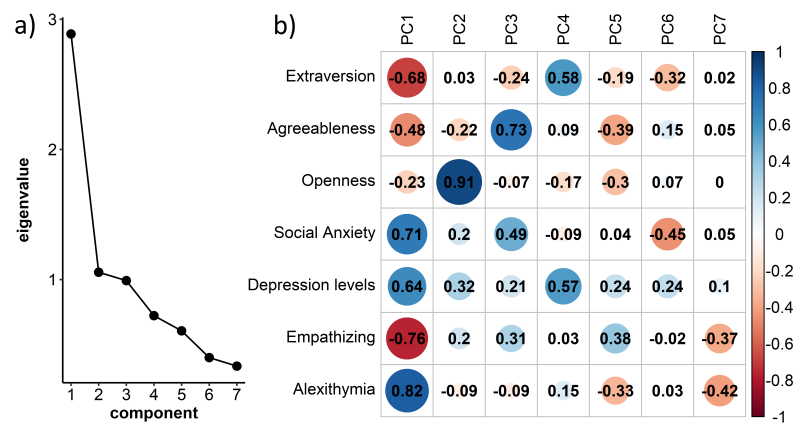

Figure 3: Results of a principal component analysis (PCA) applied to variables which correlated with attention to faces. (a) shows the factors' eigenvalues in a scree plot, while (b) shows correlations between each factor and each variable.

\section{Discussion}

Previous research observed consistent differences in people's attentional preference for faces but remained ambiguous towards the possibility to infer psychological traits from this behavioral marker. We found that attention to faces was positively associated with openness to experience, extraversion, agreeableness and empathizing while being negatively associated with social anxiety, depression levels and alexithymia. In addition, we identified a common factor which may be best understood as general psychopathology that explained $41 \%$ of the variance in these variables and was correlated with face preference at $\mathrm{r}=-0.36$.

Both a positive correlation between attention towards faces and extraversion as well as agreeableness was reported before (Wu et al. 2014), although other studies did not observe this effect (Guy et al. 2019; Haas et al. 2019) and, unlike the present study, a previous study observed a negative correlation between attention towards faces and openness to experience (Wu et al. 2014). A negative correlation between attention to faces and social anxiety corresponds to clinical reports of SAD (Schneier et al. 2011), although previous studies did not consistently observe this effect during the viewing of static images (Brunet et al. 2009; Wieser et al. 2009; Moukheiber et al. 2010; Weeks, Howell, and Goldin 2013; Guy et al. 2019; Rubo, Huestegge, and Gamer 2020). Negative correlations between attention towards faces and depression levels (which were previously found to correlate with attention towards sad faces; Foster et al. 2020) and alexithymia (which is associated with poorer recognition of emotional expressions in faces; Grynberg et al. 2012; Fujiwara et al. 2017) have no direct equivalent in the literature, but may be seen to generally comply with previously observed patterns. Although the present study did not observe a correlation between attention towards faces and systemizing - which would correspond to previous observations of reduced face preference in ASD and autistic traits (Volkmar et al. 2004; Senju and Johnson 2009; Wang et al. 2015), which was, however, not observed by Guy et al. (2019) - the positive correlation between attention towards faces and empathizing (which is characterized as a counterpart to autistic traits) may imply a similar notion.

With correlations between attentional preferences towards faces and several psychological measures, attention data in the present study cannot be directly linked to a specific characteristic (e.g., dissociate if a person's reduced preference for faces is more likely to reflect low levels of extraversion or high levels of social anxiety). This relative lack of specificity is further reflected in the presence of a strong common factor among the variables associated with attentional preferences to faces. Such an overlap between theoretically distinguishable measures were reported before. For instance, a substantial body of research documents correlations between anxiety and depression levels (Eysenck and Fajkowska 2017), depression levels and (reduced) extraversion (Watson et al. 2019), social anxiety and neuroticism as well as (reduced) extraversion (Kaplan et al. 2015) or social anxiety and alexithymia (Panayiotou et al. 2018). It was even observed that mental disorders are best explained along a structure incorporating a single psychopathology dimension at its core, termed $p$-factor, or, in short, p (Lahey et al. 2012; Caspi et al. 2014). The dominant factor among variables associated with attention towards faces corresponds well to $\mathrm{p}$ with its positive association with social anxiety, depression levels and alexithymia as well as its negative association with extraversion and empathizing. Agreeableness and openness furthermore both loaded negatively on $p$, albeit these two variables had even stronger loadings on other factors.

It may appear plausible to more specifically characterize the dominant first factor among correlates of face preference as internalizing, a transdiagnostic factor which includes depressiveness, anxiety and social anxiety 
(Krueger and Eaton 2015). However, the factor observed here does not perfectly fit with internalizing and may partly overlap with its counterpart, externalizing, which accounts for antisociality. Alternatively, the dominant factor could largely represent social aversion since extraversion, agreeableness, social anxiety and empathizing directly refer to the processing of social situations and depressiveness and alexithymia can contain elements of impaired social functioning. However, note that impairments in social functioning are not specific for individual forms of psychopathology but are found in a large variety of mental disorders (Derntl and Habel 2011; Gallagher and Varga 2015). Avoiding to interpret our findings with an unwarranted level of specificity, we cautiously retain the default assumption expressed in (Caspi et al. 2014) that the dominant factor observed here relates to p. Future research may employ an even broader range of self-report measures to more comprehensively assess if psychopathology, internalizing, social aversion or a different construct best accounts for reduced face preferences.

Since p represents a latent variable and cannot be directly assessed, a practical question concerns the most parsimonious assessment of data which explain variance in face preference. The present finding that social anxiety levels stood out as only variable to explain face preference above and beyond a model consisting of personality factors highlights that this variable may hold practical utility in explaining and understanding face preferences.

Attention patterns towards images in an internet browser were overall comparable with data from eye-tracking studies, with consistent differences in face preferences across images $(\alpha=0.88)$ and a stronger tendency to attend to faces showing direct gaze. This points towards the validity of this method to approximate eye fixations as demonstrated by (Kim et al. 2017). Time spent attending to faces was relatively low at an average of $17 \%$ of stimulus presentation time (and $29 \%$ in the first 3 seconds of stimulus presentation) compared with $55 \%$ in a study by (Guy et al. 2019) (where stimuli were presented for 3 seconds). This difference may result from a different assessment technique, but could also be due to the selection of images which show a rich environment compared with more inconspicuous backgrounds used in several images in previous studies (Xu et al. 2014; Guy et al. 2019; Haas et al. 2019) (for an example image see https://www . nature.com/articles/s41598-019-47110-x/figures/4). Future research should resolve if visually rich environments draw attention away from faces and if this process is modulated by psychological traits.

Several limitations of this study should be noted. Firstly, generalizability towards other environments and specifically towards real-life situations may be limited. Several researchers have noted that real social encounters differ qualitatively from the viewing of images in that they provide opportunities for (and possibly fear of) social interactions (Gobel, Kim, and Richardson 2015; Risko, Richardson, and Kingstone 2016). In real-life situations, a tendency to attend to faces was found to be weaker (Foulsham, Walker, and Kingstone 2011; Cañigueral, Ward, and Hamilton 2020) and to be more strongly influenced by social anxiety (Rubo, Huestegge, and Gamer 2020). Participants in the present study were predominantly drawn from a student population, with overall low levels of psychopathology on several measures (e.g. social anxiety, trait anxiety, eating psychopathology and systemizing). While gaze preference was found to discriminate between individuals differing in these ranges of psychopathology, it remains unclear if a discrimination of individuals differing in higher ranges of psychopathology is similarly possible. Gaze preferences were tested for associations with a total of 16 different self-report measures (seven of which showed statistically significant correlations), indicating that results could contain alpha errors. While findings converged into a consistent pattern and showed satisfactory stability across two different sets of stimuli, replications in different datasets are needed.

In summary, we found robust inter-individual differences in face preference which were associated with openness to experience, extraversion, agreeableness and empathizing as well as reduced social anxiety, depression levels and alexithymia. While faces showing direct gaze were attended to longer compared to faces showing averted gaze, correlations between face preference and psychological traits emerged consistently across both types of images. A common factor among variables associated with face preference resembles general psychopathology, but future research should test if a more specific interpretation as an individual facet of psychopathology is justifiable. The overlap between personality constructs and clinical characteristics within a factor linked to face preference corroborates the notion that characterizations of dysfunctional personality features should more strongly connect with broader conceptualizations of personality (Bagby and Widiger 2018). Behavioral markers such as face preference may inform and help to structure the establishment of such conceptualizations. 


\section{References}

Adolphs, Ralph. 2010. "Conceptual Challenges and Directions for Social Neuroscience." Neuron 65 (6): 752-67. https://doi.org/10.1016/j.neuron.2010.03.006.

Bagby, R. Michael, James D. A. Parker, and Graeme J. Taylor. 2020. "Twenty-Five Years with the 20Item Toronto Alexithymia Scale." Journal of Psychosomatic Research 131 (April): 109940. https: //doi.org/10.1016/j.jpsychores. 2020.109940.

Bagby, R. Michael, and Thomas A. Widiger. 2018. "Five Factor Model Personality Disorder Scales: An Introduction to a Special Section on Assessment of Maladaptive Variants of the Five Factor Model." Psychological Assessment 30 (1): 1-9. https://doi.org/10.1037/pas0000523.

Berenson, Kathy R., Anett Gyurak, Özlem Ayduk, Geraldine Downey, Matthew J. Garner, Karin Mogg, Brendan P. Bradley, and Daniel S. Pine. 2009. "Rejection Sensitivity and Disruption of Attention by Social Threat Cues." Journal of Research in Personality 43 (6): 1064-72. https://doi.org/10.1016/j. jrp.2009.07.007.

Bradley, Brendan P., Karin Mogg, Sara J. Falla, and Lucy R. Hamilton. 1998. "Attentional Bias for Threatening Facial Expressions in Anxiety: Manipulation of Stimulus Duration." Cognition 83 Emotion 12 (6): 737-53. https://doi.org/10.1080/026999398379411.

Brunet, Paul M., Jennifer J. Heisz, Catherine J. Mondloch, David I. Shore, and Louis A. Schmidt. 2009. "Shyness and Face Scanning in Children." Journal of Anxiety Disorders 23 (7): 909-14. https://doi. org/10.1016/j.janxdis.2009.05.009.

Cañigueral, Roser, Jamie Ward, and Antonia Hamilton. 2020. "Effects of Being Watched on Eye Gaze and Facial Displays of Typical and Autistic Individuals During Conversation." Autism, August, 136236132095169. https://doi.org/10.1177/1362361320951691.

Cardi, Valentina, Rosalia Di Matteo, Freya Corfield, and Janet Treasure. 2012. "Social Reward and Rejection Sensitivity in Eating Disorders: An Investigation of Attentional Bias and Early Experiences." The World Journal of Biological Psychiatry 14 (8): 622-33. https://doi.org/10.3109/15622975.2012.665479.

Carver, Charles S., and Jennifer Connor-Smith. 2010. "Personality and Coping." Annual Review of Psychology 61 (1): 679-704. https://doi.org/10.1146/annurev.psych.093008.100352.

Caspi, Avshalom, Renate M Houts, Daniel W Belsky, Sidra J Goldman-Mellor, HonaLee Harrington, Salomon Israel, Madeline H Meier, et al. 2014. "The P Factor: One General Psychopathology Factor in the Structure of Psychiatric Disorders?" Clinical Psychological Science 2 (2): 119-37.

Cerf, M., E. P. Frady, and C. Koch. 2009. "Faces and Text Attract Gaze Independent of the Task: Experimental Data and Computer Model." Journal of Vision 9 (12): 10-10. https://doi.org/10.1167/ 9.12.10.

Chamorro-Premuzic, Tomas, Adrian Furnham, and Phillip L. Ackerman. 2006. "Ability and Personality Correlates of General Knowledge." Personality and Individual Differences 41 (3): 419-29. https: //doi.org/10.1016/j.paid.2005.11.036.

Derntl, Birgit, and Ute Habel. 2011. "Deficits in Social Cognition: A Marker for Psychiatric Disorders?" European Archives of Psychiatry and Clinical Neuroscience 261 (S2): 145-49. https://doi.org/10. 1007/s00406-011-0244-0.

Ehrlich, Katherine B., Sarah A. Gerson, Ross E. Vanderwert, Erin N. Cannon, and Nathan A. Fox. 2015. "Hypervigilance to Rejecting Stimuli in Rejection Sensitive Individuals: Behavioral and Neurocognitive Evidence." Personality and Individual Differences 85 (October): 7-12. https://doi.org/10.1016/j . paid.2015.04.023.

Eysenck, Michael W., and Małgorzata Fajkowska. 2017. "Anxiety and Depression: Toward Overlapping and Distinctive Features." Cognition and Emotion 32 (7): 1391-1400. https://doi.org/10.1080/02699931. 2017.1330255.

Farroni, T., G. Csibra, F. Simion, and M. H. Johnson. 2002. "Eye Contact Detection in Humans from Birth." Proceedings of the National Academy of Sciences 99 (14): 9602-5. https://doi.org/10.1073/ pnas. 152159999. 
Foster, Claire E., Max Owens, Anastacia Y. Kudinova, and Brandon E. Gibb. 2020. "Attentional Biases to Emotional Faces Among Women with a History of Single Episode Versus Recurrent Major Depression." Cognition and Emotion 35 (1): 193-98. https://doi.org/10.1080/02699931.2020.1802228.

Foulsham, Tom, Esther Walker, and Alan Kingstone. 2011. "The Where, What and When of Gaze Allocation in the Lab and the Natural Environment." Vision Research 51 (17): 1920-31. https: //doi.org/10.1016/j.visres.2011.07.002.

Freeth, Megan, Tom Foulsham, and Alan Kingstone. 2013. "What Affects Social Attention? Social Presence, Eye Contact and Autistic Traits." Edited by Kevin Paterson. PLoS ONE 8 (1): e53286. https://doi.org/10.1371/journal.pone.0053286.

Fujiwara, Esther, Veronica L. Kube, Daniel Rochman, Alexander K. Macrae-Korobkov, and Vanessa Peynenburg and. 2017. "Visual Attention to Ambiguous Emotional Faces in Eating Disorders: Role of Alexithymia." European Eating Disorders Review 25 (6): 451-60. https://doi.org/10.1002/erv.2535.

Furnham, Adrian, Viren Swami, Adriane Arteche, and Tomas Chamorro-Premuzic. 2008. "Cognitive Ability, Learning Approaches and Personality Correlates of General Knowledge." Educational Psychology 28 (4): 427-37. https://doi.org/10.1080/01443410701727376.

Gallagher, Shaun, and Somogy Varga. 2015. "Social Cognition and Psychopathology: A Critical Overview." World Psychiatry 14 (1): 5-14. https://doi.org/10.1002/wps. 20173.

Gobel, Matthias S., Heejung S. Kim, and Daniel C. Richardson. 2015. "The Dual Function of Social Gaze." Cognition 136 (March): 359-64. https://doi.org/10.1016/j.cognition.2014.11.040.

Gosling, Samuel D., and Winter Mason. 2015. "Internet Research in Psychology." Annual Review of Psychology 66 (1): 877-902. https://doi.org/10.1146/annurev-psych-010814-015321.

Greenberg, David M, Varun Warrier, Carrie Allison, and Simon Baron-Cohen. 2018. "Testing the EmpathizingSystemizing Theory of Sex Differences and the Extreme Male Brain Theory of Autism in Half a Million People." Proceedings of the National Academy of Sciences 115 (48): 12152-7.

Grynberg, Delphine, Betty Chang, Olivier Corneille, Pierre Maurage, Nicolas Vermeulen, Sylvie Berthoz, and Olivier Luminet. 2012. "Alexithymia and the Processing of Emotional Facial Expressions (EFEs): Systematic Review, Unanswered Questions and Further Perspectives." Edited by Leonardo Fontenelle. PLoS ONE 7 (8): e42429. https://doi.org/10.1371/journal.pone.0042429.

Guy, Nitzan, Hagar Azulay, Rasha Kardosh, Yarden Weiss, Ran R. Hassin, Salomon Israel, and Yoni Pertzov. 2019. "A Novel Perceptual Trait: Gaze Predilection for Faces During Visual Exploration." Scientific Reports 9 (1). https://doi.org/10.1038/s41598-019-47110-x.

Haas, Benjamin de, Alexios L. Iakovidis, D. Samuel Schwarzkopf, and Karl R. Gegenfurtner. 2019. "Individual Differences in Visual Salience Vary Along Semantic Dimensions." Proceedings of the National Academy of Sciences, May, 201820553. https://doi.org/10.1073/pnas. 1820553116.

Hagen, Elisabeth A. H. von dem, and Naomi Bright. 2016. "High Autistic Trait Individuals Do Not Modulate Gaze Behaviour in Response to Social Presence but Look Away More When Actively Engaged in an Interaction." Autism Research 10 (2): 359-68. https://doi.org/10.1002/aur.1666.

Harrison, A., S. Sullivan, K. Tchanturia, and J. Treasure. 2010. "Emotional Functioning in Eating Disorders: Attentional Bias, Emotion Recognition and Emotion Regulation." Psychological Medicine 40 (11): $1887-97$. https://doi .org/10.1017/s0033291710000036.

Heine, Steven J., and Emma E. Buchtel. 2009. "Personality: The Universal and the Culturally Specific." Annual Review of Psychology 60 (1): 369-94. https://doi.org/10.1146/annurev.psych.60.110707. 163655.

Hessels, Roy S., Gijs A. Holleman, Tim H. W. Cornelissen, Ignace T. C. Hooge, and Chantal Kemner. 2018. "Eye Contact Takes Two Autistic and Social Anxiety Traits Predict Gaze Behavior in Dyadic Interaction." Journal of Experimental Psychopathology 9 (2): jep.062917. https://doi.org/10.5127/jep.062917.

Hsu, David T., and Johanna M. Jarcho. 2020. "Next up for Psychiatry: Rejection Sensitivity and the Social Brain." Neuropsychopharmacology 46 (1): 239-40. https://doi.org/10.1038/s41386-020-00802-9. 
Hunnius, Sabine, and Reint H. Geuze. 2004. "Developmental Changes in Visual Scanning of Dynamic Faces and Abstract Stimuli in Infants: A Longitudinal Study." Infancy 6 (2): 231-55. https://doi.org/10. 1207/s15327078in0602_5.

Joormann, Jutta, and Ian H. Gotlib. 2007. "Selective Attention to Emotional Faces Following Recovery from Depression." Journal of Abnormal Psychology 116 (1): 80-85. https://doi.org/10.1037/0021-843x. 116.1.80.

Kaplan, Simona C., Cheri A. Levinson, Thomas L. Rodebaugh, Andrew Menatti, and Justin W. Weeks. 2015. "Social Anxiety and the Big Five Personality Traits: The Interactive Relationship of Trust and Openness." Cognitive Behaviour Therapy 44 (3): 212-22. https://doi.org/10.1080/16506073.2015.1008032.

Kim, Nam Wook, Zoya Bylinskii, Michelle A. Borkin, Krzysztof Z. Gajos, Aude Oliva, Fredo Durand, and Hanspeter Pfister. 2017. "BubbleView: An Interface for Crowdsourcing Image Importance Maps and Tracking Visual Attention." ACM Transactions on Computer-Human Interaction 24 (5): 1-40. https://doi.org/10.1145/3131275.

Kraines, Morganne A., Lucas J. A. Kelberer, and Tony T. Wells. 2018. "Rejection Sensitivity, Interpersonal Rejection, and Attention for Emotional Facial Expressions." Journal of Behavior Therapy and Experimental Psychiatry 59 (June): 31-39. https://doi.org/10.1016/j.jbtep.2017.11.004.

Krueger, Robert F., and Nicholas R. Eaton. 2015. "Transdiagnostic Factors of Mental Disorders." World Psychiatry 14 (1): 27-29. https://doi.org/10.1002/wps. 20175.

Lahey, Benjamin B., Brooks Applegate, Jahn K. Hakes, David H. Zald, Ahmad R. Hariri, and Paul J. Rathouz. 2012. "Is There a General Factor of Prevalent Psychopathology During Adulthood?" Journal of Abnormal Psychology 121 (4): 971-77. https://doi.org/10.1037/a0028355.

MacLeod, Colin, Ben Grafton, and Lies Notebaert. 2019. "Anxiety-Linked Attentional Bias: Is It Reliable?" Annual Review of Clinical Psychology 15 (1): 529-54. https://doi.org/10.1146/ annurev-clinpsy-050718-095505.

Matthews, Gerald, Ian J. Deary, and Martha C. Whiteman. 2003. Personality Traits. Cambridge University Press. https://doi.org/10.1017/cbo9780511812736.

Matzen, Laura E., Mallory C. Stites, and Zoe. N. Gastelum. 2021. "Studying Visual Search Without an Eye Tracker: An Assessment of Artificial Foveation." Cognitive Research: Principles and Implications 6 (1). https://doi.org/10.1186/s41235-021-00304-2.

Morrison, Amanda S., and Richard G. Heimberg. 2013. "Social Anxiety and Social Anxiety Disorder." Annual Review of Clinical Psychology 9 (1): 249-74. https://doi.org/10.1146/ annurev-clinpsy-050212-185631.

Moukheiber, Albert, Gilles Rautureau, Fernando Perez-Diaz, Robert Soussignan, Stéphanie Dubal, Roland Jouvent, and Antoine Pelissolo. 2010. "Gaze Avoidance in Social Phobia: Objective Measure and Correlates." Behaviour Research and Therapy 48 (2): 147-51. https://doi.org/10.1016/j.brat.2009. 09.012 .

Murphy, Ryan O., Kurt A. Ackermann, and Michel Handgraaf. 2011. "Measuring Social Value Orientation." Judgment and Decision Making 6 (8): 771-81. https://doi.org/10.2139/ssrn. 1804189.

Myowa-Yamakoshi, Masako, Masaki Tomonaga, Masayuki Tanaka, and Tetsuro Matsuzawa. 2003. "Preference for Human Direct Gaze in Infant Chimpanzees (Pan Troglodytes)." Cognition 89 (2): 113-24. https: //doi.org/10.1016/s0010-0277(03)00071-4.

Panayiotou, Georgia, Chrysanthi Leonidou, Elena Constantinou, and Michalis P. Michaelides. 2018. "SelfAwareness in Alexithymia and Associations with Social Anxiety." Current Psychology 39 (5): 1600-1609. https://doi.org/10.1007/s12144-018-9855-1.

Pletzer, Jan Luca, Daniel Balliet, Jeff Joireman, D. Michael Kuhlman, Sven C. Voelpel, Paul A. M. Van Lange, and Mitja Back. 2018. "Social Value Orientation, Expectations, and Cooperation in Social Dilemmas: A MetaAnalysis." European Journal of Personality 32 (1): 62-83. https://doi.org/10.1002/per.2139.

Risko, Evan F., Daniel C. Richardson, and Alan Kingstone. 2016. "Breaking the Fourth Wall of Cognitive Science." Current Directions in Psychological Science 25 (1): 70-74. https://doi.org/10.1177/ 0963721415617806. 
Rubo, Marius, and Matthias Gamer. 2018. "Social Content and Emotional Valence Modulate Gaze Fixations in Dynamic Scenes." Scientific Reports 8 (1). https://doi.org/10.1038/s41598-018-22127-w.

Rubo, Marius, Lynn Huestegge, and Matthias Gamer. 2020. "Social Anxiety Modulates Visual Exploration in Real Life but Not in the Laboratory." British Journal of Psychology 111 (2): 233-45. https: //doi.org/10.1111/bjop.12396.

Rutherford, M. D., and Kristen M. Krysko. 2008. "Eye Direction, Not Movement Direction, Predicts Attention Shifts in Those with Autism Spectrum Disorders." Journal of Autism and Developmental Disorders 38 (10): 1958-65. https://doi.org/10.1007/s10803-008-0592-4.

Schneier, Franklin R., Thomas L. Rodebaugh, Carlos Blanco, Hillary Lewin, and Michael R. Liebowitz. 2011. "Fear and Avoidance of Eye Contact in Social Anxiety Disorder." Comprehensive Psychiatry 52 (1): 81-87. https://doi.org/10.1016/j.comppsych.2010.04.006.

Schulte-Mecklenbeck, Michael, Ryan O. Murphy, and Florian Hutzler. 2011. "Flashlight Recording Information Acquisition Online." Computers in Human Behavior 27 (5): 1771-82. https ://doi .org/10.1016/j . chb . 2011.03 .004$.

Senju, Atsushi, Toshikazu Hasegawa, and Yoshikuni Tojo. 2005. "Does Perceived Direct Gaze Boost Detection in Adults and Children with and Without Autism? The Stare-in-the-Crowd Effect Revisited." Visual Cognition 12 (8): 1474-96. https://doi.org/10.1080/13506280444000797.

Senju, Atsushi, and Mark H. Johnson. 2009. "Atypical Eye Contact in Autism: Models, Mechanisms and Development." Neuroscience 83 Biobehavioral Reviews 33 (8): 1204-14. https://doi.org/10.1016/j . neubiorev.2009.06.001.

Shalom, Dorit Ben, Ziv Ronel, Yifat Faran, Gal Meiri, Lidia Gabis, and Kimberly A. Kerns. 2013. "A Double Dissociation Between Inattentive and Impulsive Traits, on Tasks of Visual Processing and Emotion Regulation." Journal of Attention Disorders 21 (7): 543-53. https://doi.org/10.1177/ 1087054713510351.

Stein, Murray B, John R Walker, and David R Forde. 1994. "Setting Diagnostic Thresholds for Social Phobia: Considerations from a Community Survey of Social Anxiety." The American Journal of Psychiatry 151 (3): 408.

Team, R Core, and others. 2013. "R: A Language and Environment for Statistical Computing." Vienna, Austria.

Volkmar, Fred R, Catherine Lord, Anthony Bailey, Robert T Schultz, and Ami Klin. 2004. "Autism and Pervasive Developmental Disorders." Journal of Child Psychology and Psychiatry 45 (1): 135-70.

Wang, Shuo, Ming Jiang, Xavier Morin Duchesne, Elizabeth A. Laugeson, Daniel P. Kennedy, Ralph Adolphs, and Qi Zhao. 2015. "Atypical Visual Saliency in Autism Spectrum Disorder Quantified Through ModelBased Eye Tracking." Neuron 88 (3): 604-16. https://doi.org/10.1016/j.neuron.2015.09.042.

Watson, David, Kasey Stanton, Shereen Khoo, Stephanie Ellickson-Larew, and Sara M. Stasik-O'Brien. 2019. "Extraversion and Psychopathology: A Multilevel Hierarchical Review." Journal of Research in Personality 81 (August): 1-10. https://doi.org/10.1016/j.jrp.2019.04.009.

Weeks, Justin W., Ashley N. Howell, and Philippe R. Goldin. 2013. "Gaze Avoidance in Social Anxiety Disorder." Depression and Anxiety 30 (8): 749-56. https://doi.org/10.1002/da.22146.

Wieser, Matthias J., Paul Pauli, Georg W. Alpers, and Andreas Mühlberger. 2009. "Is Eye to Eye Contact Really Threatening and Avoided in Social Anxiety?An Eye-Tracking and Psychophysiology Study." Journal of Anxiety Disorders 23 (1): 93-103. https://doi.org/10.1016/j.janxdis.2008.04.004.

Wu, David, Walter F. Bischof, Nicola C. Anderson, Tanya Jakobsen, and Alan Kingstone. 2014. "The Influence of Personality on Social Attention." Personality and Individual Differences 60 (April): 25-29. https://doi.org/10.1016/j.paid.2013.11.017.

Xu, J., M. Jiang, S. Wang, M. S. Kankanhalli, and Q. Zhao. 2014. "Predicting Human Gaze Beyond Pixels." Journal of Vision 14 (1): 28-28. https://doi.org/10.1167/14.1.28. 


\title{
Supplementary to: Reduced Attention to Faces in IMAGES IS ASSOCIATED WITH PSYCHOPATHOLOGY
}

\author{
Marius Rubo \\ Clinical Psychology and Psychotherapy \\ University of Fribourg \\ Fribourg, Switzerland \\ marius.rubo@unifr.ch \\ Ivo Käthner \\ Department of Psychology I, Biological Psychology, Clinical Psychology and Psychotherapy \\ University of Würzburg \\ Würzburg, Germany \\ ivo.käthner@uni-wuerzburg. de \\ Simone Munsch \\ Clinical Psychology and Psychotherapy \\ University of Fribourg \\ Fribourg, Switzerland \\ simone.munsch@unifr.ch
}

\section{Supplementary Methods}

\subsection{Weblinks to images}

Table S1 lists the weblinks to the images used in this study. Some of the images were cut and resized for the use of the present study. These modified versions of the original images are available upon request. 
Table S1: Weblinks to the images used in this study.

\begin{tabular}{|c|c|}
\hline \multicolumn{2}{|c|}{ Images with Direct Gaze } \\
\hline 1 & https://commons.wikimedia.org/wiki/File:Kawah-Ijen_Indonesia_Ijen-Sulfur-Miner-01.jpg \\
\hline 2 & https://commons.wikimedia.org/wiki/File:Tachileik_Myanmar_Kayan-People-Woman-03.jpg \\
\hline 3 & https://commons.wikimedia.org/wiki/File:Petrol_station_in_Bénin.jpg \\
\hline 4 & https://commons.wikimedia.org/wiki/File:Young_vendor_in_a_grocery_store_in_Don_Som_(2).jpg \\
\hline 5 & https://commons.wikimedia.org/wiki/File:India___Varanasi_paper_bag_maker_-_0078.jpg \\
\hline 6 & https://commons.wikimedia.org/wiki/File:India_-_Kolkata_electricity_meters_-_3832.jpg \\
\hline 7 & https://commons.wikimedia.org/wiki/File:Hue_Vietnam_Citadel-of-Hu-21.jpg \\
\hline 8 & $\begin{array}{l}\text { https://commons.wikimedia.org/wiki/File:Comercio_en_la_plaza_del_9_de_abril_de_1947, } \\
\text { _Tánger,_Marruecos,_2015-12-11,_DD_77.JPG }\end{array}$ \\
\hline 9 & https://commons.wikimedia.org/wiki/File:The_water_transfer.jpg \\
\hline 10 & https://commons.wikimedia.org/wiki/File:Hualien_Taiwan_Farmer-with-his-water-buffalo-01. \\
\hline \multicolumn{2}{|c|}{ Images with Averted Gaze } \\
\hline 1 & $\begin{array}{l}\text { https://commons.wikimedia.org/wiki/File:04-09-12-Schaupflügen-Fahrenwalde-RalfR-IMG_1232. } \\
\text { jpg }\end{array}$ \\
\hline 2 & $\begin{array}{l}\text { https://commons.wikimedia.org/wiki/File:20191205_Haveli_Khazanchi,_Gali_Khazanchi,_Old_ } \\
\text { Delhi_0632_6743.jpg }\end{array}$ \\
\hline 3 & https://commons.wikimedia.org/wiki/File:Seller,_rubber_hoops_004.JPG \\
\hline 4 & https://commons.wikimedia.org/wiki/File:20160805_-_Inle_Lake,_Myanmar___8453_Dx0.jpg \\
\hline 5 & $\begin{array}{l}\text { https://commons.wikimedia.org/wiki/File:Boy_plowing_with_a_tractor_at_sunset_in_Don_Det, } \\
\text { _Laos.jpg }\end{array}$ \\
\hline 6 & https://commons.wikimedia.org/wiki/File:Old_Woman_of_Bhaktapur_-_Kathmandu.jpg \\
\hline 7 & https://commons.wikimedia.org/wiki/File:Fishing_boy_in_Laos.jpg \\
\hline 8 & https://commons.wikimedia.org/wiki/File:Horse_shrimpers_of_Oostduinkerke_(DSCF9740).jpg \\
\hline 9 & https://commons.wikimedia.org/wiki/File:Porto_July_2009-8.jpg \\
\hline 10 & https://commons.wikimedia.org/wiki/File:Reading_a_newspaper._Catania,_Italy.jpg \\
\hline
\end{tabular}

\subsection{Self-Report Measures}

Personality Traits were assessed using the German version of the 21-items short form of the Big Five Inventory which include extraversion, agreeableness, conscientiousness, neuroticism, and openness to experience (BFI-K; Rammstedt and John 2005). Items ask for the agreement with statements on perceptions about oneself and are scored from 1 (strongly disagree) to 5 (strongly agree).

Social Anxiety levels were assessed using the German translation (Stangier et al. 1999) of a short version of the Social Interaction Anxiety Scale (SIAS-6; Peters et al. 2012). The SIAS-6 is a 6-item shortened versions of the 20 -item original scale. Items are rated on a 5 -point Likert scale $(0=$ Not at all characteristic or true of me, $4=$ Extremely characteristic or true of me). Correlations with the long version (Mattick and Clarke 1998) were reported to be high $(\mathrm{r}=.88$; Peters et al. 2012).

Rejection Sensitivity was assessed using a German translation of the Adult Rejection Sensitivity Questionnaire (A-RSQ; Berenson et al. 2013). Participants read a brief description of nine hypothetical situations in which rejection by a significant other is possible (e.g., "After a bitter argument, you call or approach your significant other because you want to make up."). Participants are asked to indicate the degree of their concern or anxiety about the outcome of each situation on a 6-point scale ranging from 1 (very unconcerned) to 6 (very concerned). Rejection sensitivity is scored by multiplying the level of concern/anxiety by the reverse of the level of acceptance expectancy.

Trait Anxiety was assessed using a the German translation of the short version of the trait part of the StateTrait Anxiety Inventory (STAI-T; Grimm 2009; Spielberger et al. 1983). The 10 items ask for agreement on an eight-level Likert scale ranging from "not at all" to "absolutely".

Depression levels were assessed using the German version of the Patient Health Questionnaire (PHQ-9; Kroenke, Spitzer, and Williams 2001; Grafe et al. 2004) which consists of nine items. Participants are asked to report on the presence of nine problems in the last 2 weeks on a 4-point scale ranging from "not at all" (0 points) to "nearly every day" ( 3 points). The scores for symptom severity are 5-9 for mild, 10-14 for moderate, 15-19 for moderately severe and 20-27 for severe.

Eating Psychopathology was assessed using a brief German version of the Eating Disorder Examination Questionnaire (EDE-Q8; Kliem et al. 2016). The 8 Items ask participants to rate various aspects of eating psychopathology on a 7-point scale (ranging from " 1 - no day" to " 7 - every day") for the past 28 days. 
Systemizing and Empathizing were assessed using German translations of the Empathy Quotient and the Systemizing Quotient (EQ-10 and SQ-R-10; Greenberg et al. 2018) which consist of ten items each. The questionnaires have conceptual overlap with those used to assess autistic traits in previous studies (Perrykkad and Hohwy 2019), show a wide distribution in the normal population (Greenberg et al. 2018) and are collectively highly predictive of autistic traits (Greenberg et al. 2018).

Alexithymia was assessed using the German version of the Toronto Alexithymia Scale (Toronto Alexithymia Scale; TAS-20; Bagby, Parker, and Taylor 1994; Franz et al. 2001). The scale consists of 20 items and was proposed to consist of three subscales (difficulty identifying feelings; externally orientated thinking; importance of emotional introspection), but due to a lack of empirical support for a three-factor structure (Franz et al. 2001; Koch et al. 2015), the present study instead employs the scale's total score.

Impulsivity was assessed using a short German version of the Barratt Impulsiveness Scale (BIS-15; Meule, Vögele, and Kübler 2011; Spinella 2007). The 15 items are grouped in the three factors nonplanning (e.g., 'I plan tasks carefully (inverted).'), motor (e.g., 'I say things without thinking.'), and attentional (e.g., 'I get easily bored when solving thought problems.') impulsivity. Items are answered on a four-point scale ranging from rarely/never to almost always/always. Scores of the short form are highly correlated with the full version ( $\mathrm{r}=0.94$; Spinella 2007).

Social Value Orientation was assessed using the six primary resource allocation decisions in the eponymous measure (SVO; Murphy, Ackermann, and Handgraaf 2011). Here, SVO is conceptualized as as the weights people assign to their own and to others' outcomes in a distribution task. Participants were asked to allocate money to a hypothetical other and to themselves in a situation characterized by reciprocal dependency, the more money participants allocated to oneself, the less the other person would receive and vice versa. SVO scores were computed as inverse tangent of the ratio of the mean allocation to oneself and to the other person. A higher SVO angle indicates a prosocial or even altruistic orientation, while a smaller SVO angle indicates more individualistic or competitive orientation. Internal consistency in the present study was computed after applying the same trigonometric operation on all individual items instead of their sum.

General Knowledge was assessed using 40 questions from a larger assessment battery used in Trepte and Verbeet (2010) covering a range of topics (history, economy, culture and science) and to not require knowledge which may be common only for the time of publication of the original question set. In each question, participants were asked to identify the correct answer among four possible answers (resulting in a chance level of $25 \%$ ).

\section{Supplementary Results}

\subsection{Self-report data}

Questionnaire descriptives are shown in Table 2.1. Data from six questionnaires (SIAS, RSQ, STAI, PHQ, EDEQ, Systemizing) showed a right-skewed distribution and were log-transformed after adding 1 for the purpose of statistical analyses, while descriptive statistics report untransformed data. 
Table S2: Sample questionnaire descriptives.

\begin{tabular}{llllll}
\hline & Mean & SD & Range & Possible Range & $\alpha$ \\
\hline Extraversion & 3.3 & 0.86 & {$[1.5,5]$} & {$[1,5]$} & 0.81 \\
Agreeableness & 3.3 & 0.73 & {$[1.25,4.75]$} & {$[1,5]$} & 0.62 \\
Conscientiousness & 3.7 & 0.72 & {$[1.75,5]$} & {$[1,5]$} & 0.78 \\
Neuroticism & 3.3 & 0.93 & {$[1,5]$} & {$[1,5]$} & 0.83 \\
Openness & 4.11 & 0.67 & {$[2.4,5]$} & {$[1,5]$} & 0.75 \\
Social Anxiety & 4.91 & 4.38 & {$[0,21]$} & {$[0,24]$} & 0.85 \\
Rejection Sensitivity & 10.03 & 4.15 & {$[2.78,25.67]$} & {$[1,36]$} & 0.74 \\
Trait Anxiety & 16.11 & 7.48 & {$[0,34.29]$} & {$[0,100]$} & 0.85 \\
Depression levels & 7.33 & 4.61 & {$[1,26]$} & {$[0,27]$} & 0.84 \\
Eating Psychopathology & 1.64 & 1.52 & {$[0,6]$} & {$[0,6]$} & 0.93 \\
Systemizing & 5.55 & 3.39 & {$[0,17]$} & {$[0,20]$} & 0.67 \\
Empathizing & 11.79 & 4.03 & {$[0,20]$} & {$[0,20]$} & 0.82 \\
Alexithymia & 46.3 & 11.11 & {$[21,87]$} & {$[20,100]$} & 0.87 \\
Impulsivity & 30.98 & 6.09 & {$[19,48]$} & {$[15,60]$} & 0.53 \\
Social Value Orientation & 38.5 & 4.47 & {$[23.2,46.42]$} & {$[20.17,51.79]$} & 0.58 \\
General Knowledge & 58.92 & 12.44 & {$[32.5,82.5]$} & {$[0,100]$} & 0.71 \\
\hline
\end{tabular}

${ }^{a}$ Range: Actual range of scores in the present sample. Possible range: Minimum and maximum scores that can be reached on each measure. $\alpha$ : Cronbach's $\alpha$.

\subsection{Attention towards faces along the time of stimulus presentation}

To investigate the temporal trajectory of attention towards faces, the percentage of time attended to faces was averaged within time bins of 500ms duration across images within each participant. Across all participants, the temporal trajectory of attention towards faces showed a distinct pattern, with more attention allocated towards faces in the first compared to the second half during each image presentation (see Figure S1). While participants attended to faces during $16.76 \%(S D=6.21 \%)$ of the time across the whole image presentation time, attention allocation towards faces was $29.04 \%(S D=8.96 \%)$ in the first three seconds, $22.94 \%(S D=$ $7.19 \%)$ in the first five seconds and $10.70 \%(S D=8.04 \%)$ in the last five seconds. 


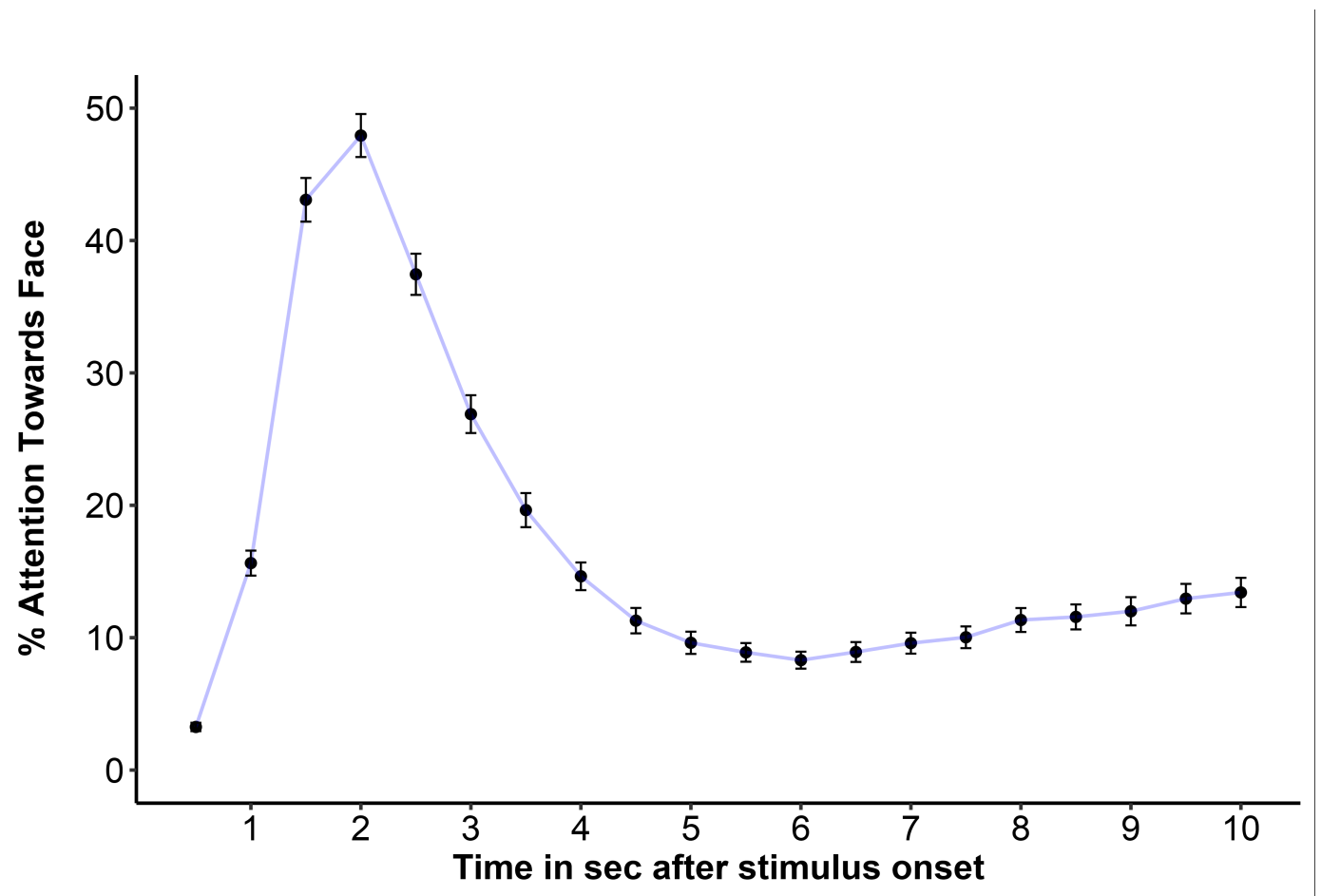

Figure S1: Temporal trajectory of attention towards faces throughout the 10 seconds of image presentation. Standard errors represent SEM.

\subsection{Distribution of attention towards faces across trials}

The percentage of time spent looking at faces (see Figure S2) showed a right-skewed distribution across all trials, with data points located between 1.42 SD below and 6.27 SD above the mean. When log-transforming data after adding 1, all data points were located between 4.32 SD below and $2.93 \mathrm{SD}$ above the mean. Attention towards the face was omitted in 18 out of 2400 trials (0.75\%). 13 participants omitted gaze at a face in one trial, one participant omitted gaze at a face in two trials and one participant omitted gaze at a face in three trials.
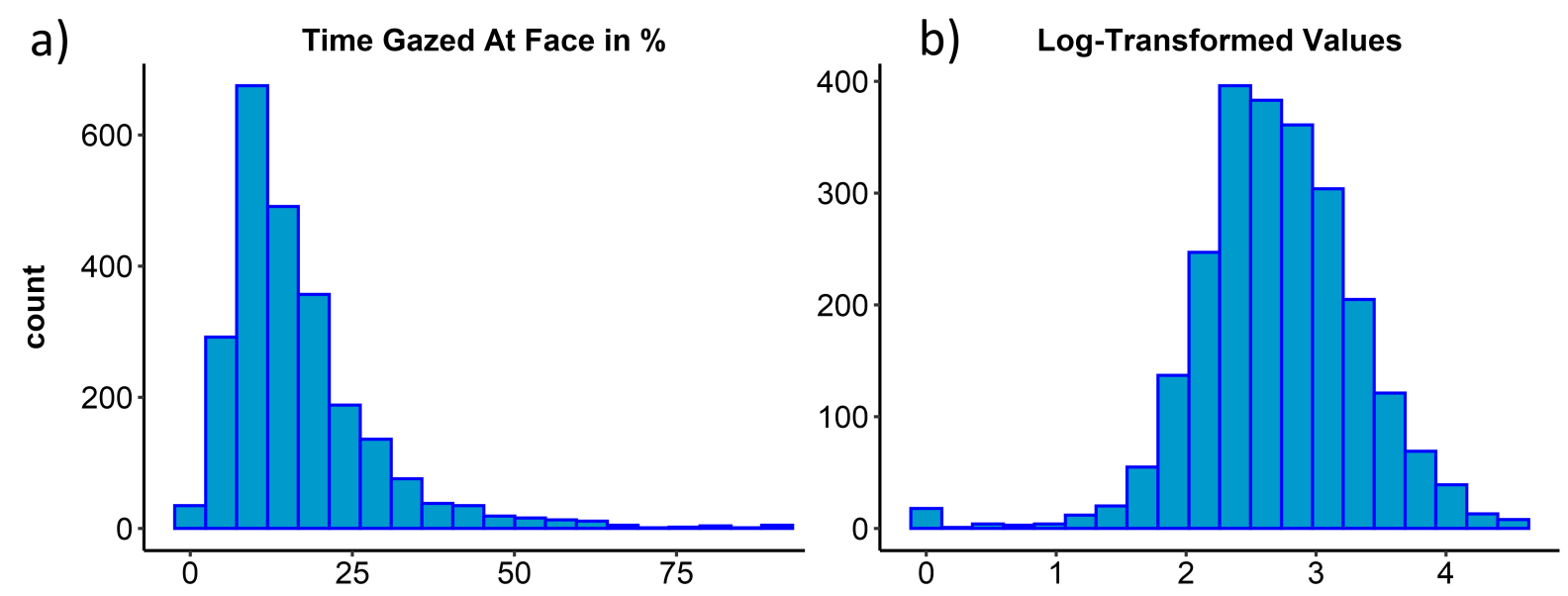

Figure S2: Percentage of time spent looking at faces across all trials (a) and the same data when logtransformed after adding 1 (b). For the purpose of statistical analyses, log-transformed data were used in this study. 


\subsection{Attention to faces showing direct or averted gaze}

Participants spent an average of $16.76 \%(S D=6.21 \%)$ of the image viewing time attending to faces. They attended to faces depicting direct gaze for longer $(M=17.19 \%, S D=6.61 \%)$ compared to faces depicting averted gaze $(M=16.33 \%, S D=6.58 \% ; \mathrm{F}(1,119)=10.99, p=.001, d=0.30[95 \%$-CI $=0.12,0.49]$; see Figure S3).
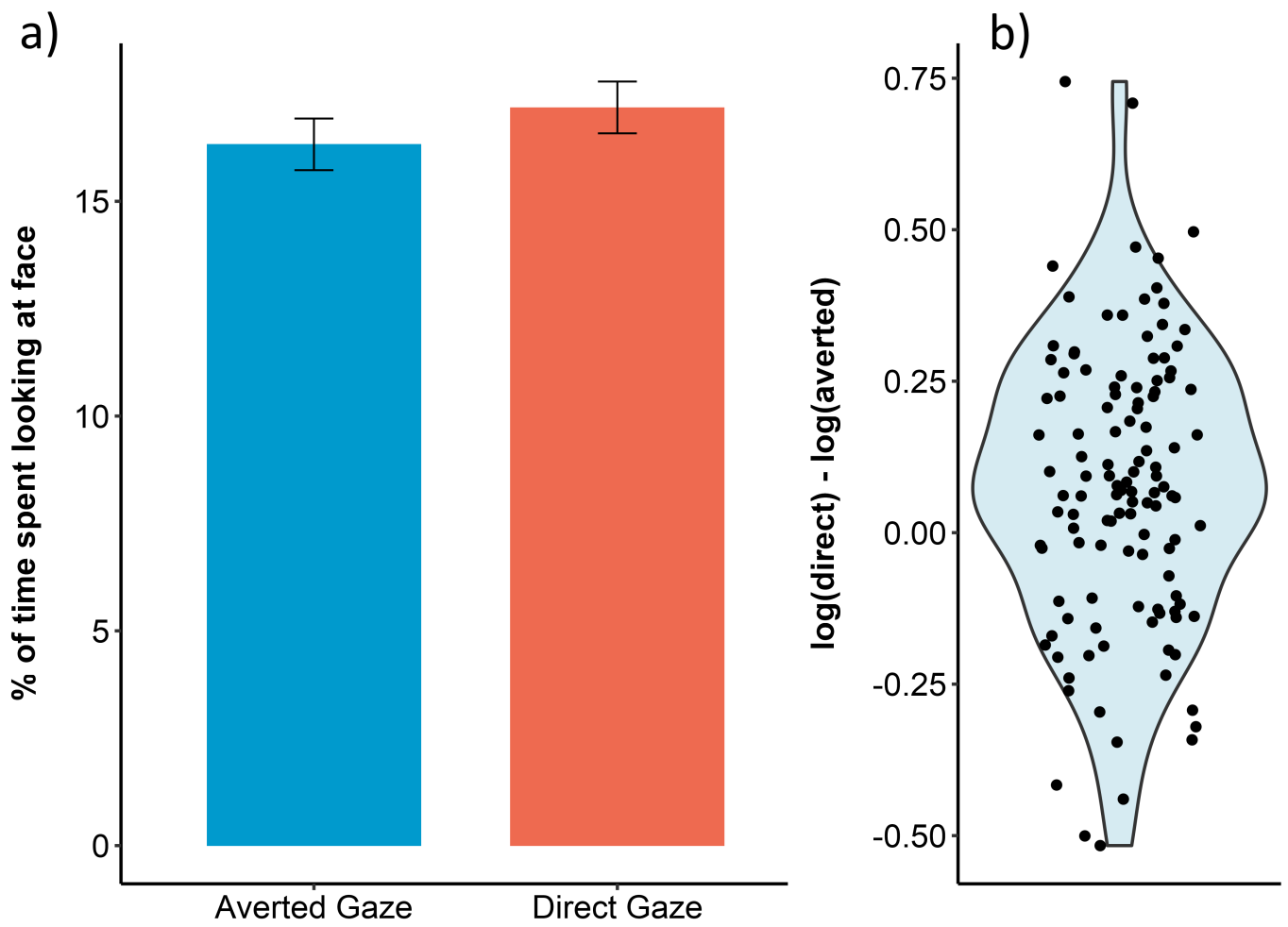

Figure S3: (a) Time spent looking at faces when they looked away from the camera (averted gaze) compared to when they looked into the camera (direct gaze). Error bars represent SEM. (b) Violin plot showing the differences between attention towards faces when depiciting direct compared to averted gaze for all 120 participants. Positions on the $\mathrm{x}$-axis are randomized for better visibility. This graph shows log-transformed data, directly corresponding to the statistical analysis described in the text.

\subsection{Correlations between attention to faces for images with direct and averted gaze}

Across all images (depicting averted gaze and direct gaze), we found a positive correlation with extraversion ( $\mathrm{r}$ $=0.21,95 \% \mathrm{CI}[0.03,0.37], \mathrm{t}(118)=2.32, p=.022)$, a positive correlation with agreeableness $(\mathrm{r}=0.24,95 \%$ CI $[0.06,0.40], \mathrm{t}(118)=2.70, p=.008)$, a (marginally significant) positive correlation with conscientiousness $(\mathrm{r}=0.16,95 \%$ CI $[-0.02,0.33], \mathrm{t}(118)=1.81, p=.074)$, a (marginally significant) negative correlation with neuroticism $(\mathrm{r}=-0.16,95 \%$ CI [-0.33, 0.02], $\mathrm{t}(118)=-1.79, p=.075)$, a positive correlation with openness $(\mathrm{r}=0.24,95 \%$ CI $[0.06,0.40], \mathrm{t}(118)=2.68, p=.008)$, a negative correlation with social anxiety $(\mathrm{r}=-0.26$, $95 \%$ CI $[-0.42,-0.08], \mathrm{t}(118)=-2.92, p=.004)$, a (marginally significant) negative correlation with rejection sensitivity $(\mathrm{r}=-0.17,95 \%$ CI $[-0.34,0.01], \mathrm{t}(118)=-1.84, p=.068)$, no correlation with trait anxiety $(\mathrm{r}=$ $-0.10,95 \%$ CI $[-0.28,0.08], \mathrm{t}(118)=-1.11, p=.271)$, a negative correlation with depression levels $(\mathrm{r}=-0.24$, $95 \%$ CI $[-0.40,-0.06], \mathrm{t}(118)=-2.64, p=.010)$, no correlation with eating psychopathology $(\mathrm{r}=0.04,95 \%$ CI $[-0.14,0.21], \mathrm{t}(118)=0.40, p=.693)$, no correlation with systemizing $(\mathrm{r}=0.01,95 \%$ CI $[-0.17,0.19]$, $\mathrm{t}(118)=0.16, p=.876)$, a positive correlation with empathizing $(\mathrm{r}=0.24,95 \% \mathrm{CI}[0.07,0.40], \mathrm{t}(118)=$ $2.71, p=.008)$, a negative correlation with alexithymia $(\mathrm{r}=-0.28,95 \%$ CI $[-0.44,-0.11], \mathrm{t}(118)=-3.18$, $p=.002)$, no correlation with impulsivity $(\mathrm{r}=-0.08,95 \%$ CI $[-0.25,0.10], \mathrm{t}(118)=-0.83, p=.409)$, no correlation with social value orientation $(\mathrm{r}=-0.09,95 \%$ CI $[-0.27,0.09], \mathrm{t}(118)=-0.98, p=.328)$ and no correlation with general knowledge $(\mathrm{r}=-0.10,95 \%$ CI $[-0.27,0.08], \mathrm{t}(118)=-1.06, p=.292)$. 
With regards to attention towards faces in images depicting averted gaze, we found no (statistically significant) correlation with extraversion $(\mathrm{r}=0.15,95 \%$ CI $[-0.03,0.32], \mathrm{t}(118)=1.63, p=.106)$, a (statistically significant) positive correlation with agreeableness $(\mathrm{r}=0.19,95 \% \mathrm{CI}[0.02,0.36], \mathrm{t}(118)=2.16, p=.033)$, a (marginally significant) positive correlation with conscientiousness $(\mathrm{r}=0.17,95 \%$ CI [-0.01, 0.34], $\mathrm{t}(118)=$ $1.85, p=.066)$, no correlation with neuroticism $(\mathrm{r}=-0.10,95 \%$ CI $[-0.27,0.08], \mathrm{t}(118)=-1.05, p=.294)$, a positive correlation with openness $(\mathrm{r}=0.23,95 \% \mathrm{CI}[0.05,0.39], \mathrm{t}(118)=2.56, p=.012)$, a negative correlation with social anxiety $(\mathrm{r}=-0.21,95 \%$ CI $[-0.38,-0.04], \mathrm{t}(118)=-2.38, p=.019)$, no correlation with rejection sensitivity $(\mathrm{r}=-0.11,95 \% \mathrm{CI}[-0.29,0.07], \mathrm{t}(118)=-1.23, p=.22)$, no correlation with trait anxiety $(\mathrm{r}=-0.06,95 \%$ CI $[-0.24,0.12], \mathrm{t}(118)=-0.65, p=.520)$, a negative correlation with depression levels $(\mathrm{r}$ $=-0.19,95 \%$ CI $[-0.35,-7.63 \mathrm{e}-03], \mathrm{t}(118)=-2.06, p=.041)$, no correlation with eating psychopathology $(\mathrm{r}$ $=0.03,95 \%$ CI $[-0.15,0.21], \mathrm{t}(118)=0.29, p=.769)$, no correlation with systemizing $(\mathrm{r}=0.03,95 \%$ CI $[-0.15,0.21], \mathrm{t}(118)=0.31, p=.757)$, a positive correlation with empathizing $(\mathrm{r}=0.23,95 \%$ CI $[0.05,0.39]$, $\mathrm{t}(118)=2.58, p=.011)$, a negative correlation with alexithymia $(\mathrm{r}=-0.27,95 \% \mathrm{CI}[-0.43,-0.10], \mathrm{t}(118)=$ $-3.04, p=.003)$, no correlation with impulsivity $(\mathrm{r}=-0.11,95 \%$ CI $[-0.28,0.07], \mathrm{t}(118)=-1.19, p=.237)$, no correlation with social value orientation $(\mathrm{r}=-0.09,95 \%$ CI $[-0.26,0.10], \mathrm{t}(118)=-0.93, p=.353)$, no correlation with general knowledge $(\mathrm{r}=-0.10,95 \%$ CI $[-0.27,0.08], \mathrm{t}(118)=-1.10, p=.274)$ and a negative correlation with the p-factor $(\mathrm{r}=-0.31,95 \%$ CI $[-0.47,-0.14], \mathrm{t}(118)=-3.60, p<.001)$.

With regards to attention towards faces in images depicting direct gaze, we found a positive correlation with extraversion $(\mathrm{r}=0.24,95 \%$ CI $[0.07,0.41], \mathrm{t}(118)=2.74, p=.007)$, a positive correlation with agreeableness $(\mathrm{r}=0.26,95 \%$ CI $[0.08,0.42], \mathrm{t}(118)=2.91, p=.004)$, no correlation with conscientiousness $(\mathrm{r}=0.14,95 \%$ CI [-0.04, 0.31], $\mathrm{t}(118)=1.54, p=.126)$ a negative correlation with neuroticism ( $\mathrm{r}=-0.21,95 \%$ CI [-0.37, $-0.03], \mathrm{t}(118)=-2.33, p=.022)$, a positive correlation with openness $(\mathrm{r}=0.22,95 \% \mathrm{CI}[0.05,0.39], \mathrm{t}(118)=$ $2.48, p=.015)$, a negative correlation with social anxiety $(\mathrm{r}=-0.27,95 \% \mathrm{CI}[-0.43,-0.10], \mathrm{t}(118)=-3.10, p$ $=.002)$, a negative correlation with rejection sensitivity $(\mathrm{r}=-0.20,95 \% \mathrm{CI}[-0.37,-0.02], \mathrm{t}(118)=-2.24, p=$ $.027)$, no correlation with trait anxiety $(\mathrm{r}=-0.13,95 \%$ CI $[-0.30,0.05], \mathrm{t}(118)=-1.44, p=.153)$, a negative correlation with depression levels $(\mathrm{r}=-0.26,95 \%$ CI $[-0.42,-0.08], \mathrm{t}(118)=-2.89, p=.004)$, no correlation with eating psychopathology $(\mathrm{r}=0.04,95 \%$ CI $[-0.14,0.22], \mathrm{t}(118)=0.45, p=.652)$, no correlation with systemizing $(\mathrm{r}=0.00,95 \%$ CI $[-0.18,0.18], \mathrm{t}(118)=-0.01, p=.989)$, a negative correlation with empathizing $(\mathrm{r}=0.23,95 \%$ CI $[0.05,0.39], \mathrm{t}(118)=2.52, p<.013)$, a negative correlation with alexithymia $(\mathrm{r}=-0.26$, $95 \%$ CI $[-0.42,-0.08], \mathrm{t}(118)=-2.92, p=.004)$, no correlation with impulsivity $(\mathrm{r}=-0.03,95 \%$ CI [-0.21, $0.15], \mathrm{t}(118)=-0.38, p=.705)$, no correlation with social value orientation $(\mathrm{r}=-0.08,95 \%$ CI $[-0.26,0.10]$, $\mathrm{t}(118)=-0.92, p=0.361)$, no correlation with general knowledge $(\mathrm{r}=-0.08,95 \%$ CI $[-0.26,0.10], \mathrm{t}(118)=$ $-0.90, p=.371)$ and a negative correlation with the $\mathrm{p}$-factor $(\mathrm{r}=-0.37,95 \%$ CI $[-0.52,-0.21], \mathrm{t}(118)=-4.36$, $p<.001)$.

\subsection{Hierarchical Analysis of Predictors for Preferential Gaze as Faces}

Results from a hierarchical analysis testing if any variable predicts attention towards faces beyond personality traits are shown in Table S3. A first all-subsets multiple regression analyses compared the predictive accuracy in models including all combinations of the three personality factors which correlated significantly with attention towards faces (extraversion, agreeableness and openness; models 1 to 8). A second all-subsets multiple regression analyses added every combination of the remaining variables which were correlated significantly with attention towards faces (social anxiety, depression levels, empathizing and alexithymia; models 9 to 23). The best performing models in each step, assessed by means of RMSE in a leave-one-out cross-validation, are printed in bold. 
Table S3: Results from a hierarchical analysis testing if any variable predicts attention towards faces beyond personality traits.

\begin{tabular}{|c|c|c|c|c|c|c|c|c|}
\hline Model & Extraversion & Agreeableness & Openness & Social Anxiety & Depression Levels & Empathizing & Alexithymia & RMSE \\
\hline 1 & & & & & & & & 1.0042 \\
\hline 2 & $\begin{array}{c}0.21 \\
{[0.03,0.39]}\end{array}$ & & & & & & & 0.9907 \\
\hline 3 & & $\begin{array}{c}0.24 \\
{[0.06,0.42]}\end{array}$ & & & & & & 0.9846 \\
\hline 4 & & & $\begin{array}{c}0.24 \\
{[0.06,0.42]}\end{array}$ & & & & & 0.9851 \\
\hline 5 & $\begin{array}{c}0.16 \\
{[-0.02,0.34]}\end{array}$ & $\begin{array}{c}0.21 \\
{[0.03,0.38]}\end{array}$ & & & & & & 0.9797 \\
\hline 6 & $\begin{array}{c}0.18 \\
{[0.00,0.36]}\end{array}$ & & $\begin{array}{c}0.22 \\
{[0.04,0.39]}\end{array}$ & & & & & 0.9787 \\
\hline 7 & & $\begin{array}{c}0.25 \\
{[0.08,0.42]}\end{array}$ & $\begin{array}{c}0.25 \\
{[0.08,0.42]}\end{array}$ & & & & & 0.9619 \\
\hline 8 & $\begin{array}{c}0.13 \\
{[-0.05,0.31]}\end{array}$ & $\begin{array}{c}0.22 \\
{[0.04,0.40]}\end{array}$ & $\begin{array}{c}0.23 \\
{[0.06,0.40]}\end{array}$ & & & & & 0.9635 \\
\hline 9 & & $\begin{array}{c}0.22 \\
{[0.05,0.39]}\end{array}$ & $\begin{array}{c}0.24 \\
{[0.07,0.40]}\end{array}$ & $\begin{array}{c}-0.22 \\
{[-0.39,-0.05]}\end{array}$ & & & & 0.9422 \\
\hline 10 & & $\begin{array}{c}0.21 \\
{[0.03,0.38]}\end{array}$ & $\begin{array}{c}0.24 \\
{[0.07,0.41]}\end{array}$ & & $\begin{array}{c}-0.18 \\
{[-0.36,-0.01]}\end{array}$ & & & 0.9503 \\
\hline 11 & & $\begin{array}{c}0.20 \\
{[0.02,0.39]}\end{array}$ & $\begin{array}{c}0.22 \\
{[0.04,0.40]}\end{array}$ & & & $\begin{array}{c}0.12 \\
{[-0.07,0.31]}\end{array}$ & & 0.9636 \\
\hline 12 & & $\begin{array}{c}0.19 \\
{[0.01,0.37]}\end{array}$ & $\begin{array}{c}0.21 \\
{[0.04,0.39]}\end{array}$ & & & & $\begin{array}{c}-0.18 \\
{[-0.36,0.00]}\end{array}$ & 0.9561 \\
\hline 13 & & $\begin{array}{c}0.21 \\
{[0.03,0.38]}\end{array}$ & $\begin{array}{c}0.24 \\
{[0.07,0.40]}\end{array}$ & $\begin{array}{c}-0.18 \\
{[-0.37,0.01]}\end{array}$ & $\begin{array}{c}-0.10 \\
{[-0.29,0.09]}\end{array}$ & & & 0.9453 \\
\hline 14 & & $\begin{array}{c}0.21 \\
{[0.02,0.39]}\end{array}$ & $\begin{array}{c}0.23 \\
{[0.05,0.40]}\end{array}$ & $\begin{array}{c}-0.21 \\
{[-0.39,-0.03]}\end{array}$ & & $\begin{array}{c}0.04 \\
{[-0.15,0.24]}\end{array}$ & & 0.9492 \\
\hline 15 & & $\begin{array}{c}0.20 \\
{[0.02,0.38]}\end{array}$ & $\begin{array}{c}0.22 \\
{[0.05,0.39]}\end{array}$ & $\begin{array}{c}-0.18 \\
{[-0.37,0.00]}\end{array}$ & & & $\begin{array}{c}-0.09 \\
{[-0.30,0.11]}\end{array}$ & 0.9479 \\
\hline 16 & & $\begin{array}{c}0.18 \\
{[-0.01,0.37]}\end{array}$ & $\begin{array}{c}0.23 \\
{[0.05,0.40]}\end{array}$ & & $\begin{array}{c}-0.17 \\
{[-0.35,0.01]}\end{array}$ & $\begin{array}{c}0.08 \\
{[-0.12,0.27]}\end{array}$ & & 0.9560 \\
\hline 17 & & $\begin{array}{c}0.18 \\
{[0.00,0.36]}\end{array}$ & $\begin{array}{c}0.22 \\
{[0.05,0.39]}\end{array}$ & & $\begin{array}{c}-0.14 \\
{[-0.33,0.05]}\end{array}$ & & $\begin{array}{c}-0.12 \\
{[-0.32,0.08]}\end{array}$ & 0.9537 \\
\hline 18 & & $\begin{array}{c}0.19 \\
{[0.00,0.37]}\end{array}$ & $\begin{array}{c}0.21 \\
{[0.03,0.39]}\end{array}$ & & & $\begin{array}{c}0.02 \\
{[-0.21,0.25]}\end{array}$ & $\begin{array}{c}-0.17 \\
{[-0.40,0.05]}\end{array}$ & 0.9630 \\
\hline 19 & & $\begin{array}{c}0.19 \\
{[0.01,0.38]}\end{array}$ & $\begin{array}{c}0.23 \\
{[0.06,0.40]}\end{array}$ & $\begin{array}{c}-0.17 \\
{[-0.37,0.03]}\end{array}$ & $\begin{array}{c}-0.10 \\
{[-0.29,0.10]}\end{array}$ & $\begin{array}{c}0.03 \\
{[-0.16,0.23]}\end{array}$ & & 0.9526 \\
\hline 20 & & $\begin{array}{c}0.19 \\
{[0.01,0.37]}\end{array}$ & $\begin{array}{c}0.22 \\
{[0.05,0.40]}\end{array}$ & $\begin{array}{c}-0.16 \\
{[-0.36,0.04]}\end{array}$ & $\begin{array}{c}-0.08 \\
{[-0.28,0.12]}\end{array}$ & & $\begin{array}{c}-0.07 \\
{[-0.28,0.14]}\end{array}$ & 0.9523 \\
\hline 21 & & $\begin{array}{c}0.20 \\
{[0.01,0.38]}\end{array}$ & $\begin{array}{c}0.22 \\
{[0.05,0.39]}\end{array}$ & $\begin{array}{c}-0.18 \\
{[-0.38,0.01]}\end{array}$ & & $\begin{array}{c}0.00 \\
{[-0.23,0.23]}\end{array}$ & $\begin{array}{c}-0.09 \\
{[-0.33,0.14]}\end{array}$ & 0.9553 \\
\hline 22 & & $\begin{array}{c}0.17 \\
{[-0.01,0.36]}\end{array}$ & $\begin{array}{c}0.22 \\
{[0.04,0.39]}\end{array}$ & & $\begin{array}{c}-0.14 \\
{[-0.33,0.05]}\end{array}$ & $\begin{array}{c}0.02 \\
{[-0.21,0.25]}\end{array}$ & $\begin{array}{c}-0.11 \\
{[-0.35,0.12]}\end{array}$ & 0.9610 \\
\hline 23 & & $\begin{array}{c}0.19 \\
{[0.00,0.38]}\end{array}$ & $\begin{array}{c}0.22 \\
{[0.05,0.40]}\end{array}$ & $\begin{array}{c}-0.16 \\
{[-0.36,0.05]}\end{array}$ & $\begin{array}{c}-0.08 \\
{[-0.29,0.12]}\end{array}$ & $\begin{array}{c}0.00 \\
{[-0.23,0.23]}\end{array}$ & {$\left[\begin{array}{c}-0.07 \\
{[-0.31,0.17]}\end{array}\right.$} & 0.9600 \\
\hline
\end{tabular}

\section{Supplementary References}

Bagby, R.Michael, James D. A. Parker, and Graeme J. Taylor. 1994. "The Twenty-Item Toronto Alexithymia ScaleI. Item Selection and Cross-Validation of the Factor Structure." Journal of Psychosomatic Research 38 (1): 23-32. https://doi.org/10.1016/0022-3999(94)90005-1.

Berenson, KR, A Gyurak, G Downey, O Ayduk, K Mogg, B Bradley, and D Pine. 2013. "Rejection Sensitivity Rs-Adult Questionnaire (a-Rsq)." Measurement Instrument Database for the Social Science.

Franz, Matthias, Christine Schneider, Ralf Schäfer, Norbert Schmitz, and Karen Zweyer. 2001. "Faktorenstruktur Und Testgüte-Kriterien Der Deutschen Version Der Toronto-Alexithymie-Skala (TAS-20) Bei Psychosomatischen Patienten." PPmP - Psychotherapie - Psychosomatik - Medizinische Psychologie 51 (2): 48-55. https://doi.org/10.1055/s-2001-10755. 
Grafe, K, S Zipfel, W Herzog, and B Lowe. 2004. "Screening for Psychiatric Disorders with the Patient Health Questionnaire (Phq). Results from the German Validation Study." Diagnostica 50 (4): 171-81.

Greenberg, David M, Varun Warrier, Carrie Allison, and Simon Baron-Cohen. 2018. "Testing the Empathizing-Systemizing Theory of Sex Differences and the Extreme Male Brain Theory of Autism in Half a Million People." Proceedings of the National Academy of Sciences 115 (48): 12152-7.

Grimm, Jürgen. 2009. "State-Trait-Anxiety Inventory Nach Spielberger. Deutsche Lang-Und Kurzversion." Methodenforum Der Universität Wien: MF-Working Paper 2.

Kliem, Sören, Thomas MöSSle, Markus Zenger, Bernhard StrauSS, Elmar Brähler, and Anja Hilbert. 2016. "The Eating Disorder Examination-Questionnaire 8: A Brief Measure of Eating Disorder Psychopathology (Ede-Q8)." International Journal of Eating Disorders 49 (6): 613-16.

Koch, Anne Sarah, Alexandra Kleiman, Ingo Wegener, Berndt Zur, Katrin Imbierowicz, Franziska Geiser, and Rupert Conrad. 2015. "Factorial Structure of the 20-Item Toronto Alexithymia Scale in a Large Sample of Somatoform Patients." Psychiatry Research 225 (3): 355-63. https://doi.org/10.1016/j . psychres.2014.12.013.

Kroenke, Kurt, Robert L Spitzer, and Janet BW Williams. 2001. "The Phq-9: Validity of a Brief Depression Severity Measure." Journal of General Internal Medicine 16 (9): 606-13.

Mattick, Richard P, and J Christopher Clarke. 1998. "Development and Validation of Measures of Social Phobia Scrutiny Fear and Social Interaction Anxiety." Behaviour Research and Therapy 36 (4): 455-70.

Meule, A, C Vögele, and A Kübler. 2011. "Psychometrische Evaluation Der Deutschen Barratt Impulsiveness Scale-Kurzversion (Bis-15)." Diagnostica 57: 126-33.

Murphy, Ryan O, Kurt A Ackermann, and Michel Handgraaf. 2011. "Measuring Social Value Orientation." Judgment and Decision Making 6 (8): 771-81.

Perrykkad, Kelsey, and Jakob Hohwy. 2019. "When Big Data Aren't the Answer." Proceedings of the National Academy of Sciences 116 (28): 13738-9. https://doi.org/10.1073/pnas.1902050116.

Peters, Lorna, Matthew Sunderland, Gavin Andrews, Ronald M Rapee, and Richard P Mattick. 2012. "Development of a Short Form Social Interaction Anxiety (Sias) and Social Phobia Scale (Sps) Using Nonparametric Item Response Theory: The Sias-6 and the Sps-6." Psychological Assessment 24 (1): 66.

Rammstedt, Beatrice, and Oliver P John. 2005. "Kurzversion Des Big Five Inventory (Bfi-K)." Diagnostica 51 (4): 195-206.

Spielberger, Charles D, Richard L Gorsuch, R Lushene, Peter R Vagg, and Gerard A Jacobs. 1983. "Manual for the State-Trait Anxiety Inventory (Palo Alto, ca, Consulting Psychologists Press)." Inc.

Spinella, Marcello. 2007. "Normative Data and a Short Form of the Barratt Impulsiveness Scale." International Journal of Neuroscience 117 (3): 359-68. https://doi.org/10.1080/00207450600588881.

Stangier, Ulrich, Thomas Heidenreich, Andrea Berardi, Ulrike Golbs, and Jürgen Hoyer. 1999. "Die Erfassung Sozialer Phobie Durch Social Interaction Anxiety Scale (Sias) Und Die Social Phobia Scale (Sps)." Zeitschrift Für Klinische Psychologie.

Trepte, Sabine, and Markus Verbeet. 2010. Allgemeinbildung in Deutschland: Erkenntnisse Aus Dem Spiegel-Studentenpisa-Test. Springer-Verlag. 